\title{
Neural Network Model Analysis for Investigation of NO Origin in a High Mountain Site
}

\author{
Eleonora Aruffo ${ }^{1, *} \mathbb{E}$, Piero Di Carlo ${ }^{1}$, Paolo Cristofanelli ${ }^{2} \mathbb{D}$ and Paolo Bonasoni ${ }^{2}$ \\ 1 Department of Psychological, Health \& Territorial Sciences, University “G. d'Annunzio” of Chieti-Pescara, \\ 66100 Chieti, Italy; piero.dicarlo@unich.it \\ 2 Institute of Atmospheric Sciences and Climate, National Research Council of Italy, 40129 Bologna, Italy; \\ p.cristofanelli@isac.cnr.it (P.C.); P.Bonasoni@isac.cnr.it (P.B.) \\ * Correspondence: eleonora.aruffo@unich.it
}

Received: 20 November 2019; Accepted: 4 February 2020; Published: 7 February 2020

\begin{abstract}
Measurements of nitrogen oxide (NO), ozone $\left(\mathrm{O}_{3}\right)$, and meteorological parameters have been carried out between September and November 2013 in a high mountain site in Central Italy at the background station of Mt. Portella (2401 m a.s.1.). Three NO plumes, with concentrations up to about $10 \mathrm{ppb}$, characterized the time series. To investigate their origin, single hidden layer feedforward neural networks (FFNs) have been developed setting the NO as the output neuron. Five different simulations have been carried out maintaining the same FFNs architecture and varying the input nodes. To find the best simulations, the number of the neurons in the hidden layer varied between 1 and 40 and 30 trials models have been evaluated for each network. Using the correlation coefficient (R), the normalized mean square error (NMSE), the fractional bias (FB), the factor of 2 (FA2) and the $t$-student test, the FFNs results suggest that two of the three NO plumes are significantly better modeled when considering the dynamical variables (with the highest $\mathrm{R}$ of 0.7996 ) as FFNs input compare to the simulations that include as input only the photochemical indexes (with the lowest R of 0.3344). In the Mt. Portella station, transport plays a crucial role for the local NO level, as demonstrated by the back-trajectories; in fact, considering also the photochemical processes, the FFNs results suggest that transport, more than local sources or the photochemistry, can explain the observed NO plumes, as confirmed by all the statistical parameters.
\end{abstract}

Keywords: artificial neural network; NO; high mountain

\section{Introduction}

Nitrogen oxides $\left(\mathrm{NO}_{\mathrm{x}}=\mathrm{NO}+\mathrm{NO}_{2}\right)$ indirectly affect the tropospheric greenhouse gas level playing a crucial role in the tropospheric ozone $\left(\mathrm{O}_{3}\right)$ budget and contributing to the formation of the secondary organic aerosols (SOAs). Their emission into the atmosphere is mainly dominated by anthropogenic sources (fossil fuel combustion-related especially to the road transport, industrial and agricultural processes, and biomass and biofuel burning) and partially associated with natural activities (lightning, soils) [1]. The European Environmental Agency in 2016 attributed 71,000 premature deaths to the $\mathrm{NO}_{2}$ in 41 European countries with an annual mean concentration of $16.3 \mu \mathrm{g} / \mathrm{m}^{3}$ [2].

$\mathrm{NO}$ and $\mathrm{NO}_{2}$ have been widely sampled in free troposphere remote sites: their origin and the role played by the long transport have been investigated. In fact, the knowledge of the pollutant levels in background high mountain sites and the understanding of the mechanisms from which they originate are crucial to evaluate the impact of anthropogenic activities with regards to ecosystem integrity [3]. In 2019, Cheng et al. [4] demonstrated that meteorological conditions significantly influence the background levels of pollutants in the Gongga Mountain station (3541 m, southwestern China) identifying potential source areas (long-range transport and/or local emissions) for their 
pollutant of interest. Bytnerowicz et al. [3] found that the estimated deposition of reactive nitrogen, among which was $\mathrm{NO}$ and $\mathrm{NO}_{2}$, monitored in 14 sites in the central Sierra Nevada Mountains and White mountains (511 m and $4346 \mathrm{~m}$, California), impact on lichen communities of these ecosystems and could potentially cause the enrichment of nutrients and the acidification levels of high mountain lakes. Even in Europe, the free troposphere chemistry variability as a function of the air masses transport has been extensively studied [5-7]. Kaiser et al. (2007) [8] investigated the $\mathrm{NO}_{\mathrm{x}}$ transport to Alpine Global Atmosphere Watch (GAW) stations by using a methodology based on trajectory studies. They found that $\mathrm{NO}_{\mathrm{x}}$, sampled in air masses with long residence time, principally originated from northwest of Europe, East Germany, Czech Republic and southeast Poland. In 2016, Okamoto and Tanimoto [9] reviewed the atmospheric chemistry observed worldwide at high-altitude mountain sites, highlighting the importance of the long-range transport in these stations. Sigmund et al. (2019) [10] classified air masses with respect to the vertical transport developing a multivariate statistical model, measured at the Zugspitze mountain observatory (Germany, $2650 \mathrm{~m}$ a.s.l.). The $\mathrm{NO}_{\mathrm{x}}$ variability between 1998 and 2009 has been studied at the high alpine site Jungfraujoch (Swiss Alps, 35,810 m a.s.l.), where the $\mathrm{NO}_{\mathrm{x}}$ did not show a long-term trend but, on the contrary, a strong interannual variation influenced by single episodes of pollution [11]. Gilge et al. [12] analyzed the long-term time series of $\mathrm{NO}_{\mathrm{x}}$ at four alpine GAW stations highlighting that the $\mathrm{NO}_{2}$ concentrations are strongly affected by anthropogenic emissions. The Po Valley is one of the more polluted areas in Europe due to its high density of population and agricultural and industrial activities. The pollution emitted in this region and its impact on trace gases observed in high mountain stations in Central Europe have been widely investigated [13-15]. The Mediterranean area, moreover, is considered a European hot spot for both air quality and climate change [16] and, consequently, the monitoring and analysis of $\mathrm{NO}_{\mathrm{x}}$ and $\mathrm{O}_{3}$ in this region are of primary importance. Cristofanelli et al. [17] investigated the $\mathrm{O}_{3}$ variability measured at the Mt. Portella station (henceforth CMP) demonstrating, by using the five-day back trajectories, that highest ozone concentrations are related to air masses transported from Central and Eastern Europe and northern Italy.

Several models have been developed to simulate the atmospheric compounds based on different approaches: box models integrating, for example, the Master Chemical Mechanism [18], mesoscale non-hydrostatic 3-D meteorological model, i.e., WRF-Chem [19], regression models (such as, multiple linear regression [20], land-use regression, supervised linear regression [21], and so on. Recently, artificial neural networks (ANNs) have been increasingly used by the scientific community to simulate and predict the atmospheric composition, focusing especially on $\mathrm{NO}_{x}, \mathrm{O}_{3}$, and particulate matters [22]. The nitrogen oxide was modeled by ANNs in the urban context [23,24]. In this work, we present simulations of NO in a free troposphere site (Mt. Portella climatological station, $2401 \mathrm{~m}$ a.s.l.), located in the middle of the Mediterranean basin, using a single hidden feedforward neural network (FFN) architecture. For our analysis, we performed 5 different simulations varying the input of the neuron to identify the origin of three NO plumes that reached the mountain station between October and November 2013. We found that the model including only the meteorological parameters related to the transport (i.e., wind speed, wind direction, and pressure) gives statistically better simulations than that considering only the photochemistry.

\section{Materials and Methods}

\subsection{Data and Site}

The data analyzed have been recorded at the high altitude climatological station CMP $\left(42^{\circ} 26^{\prime} 53^{\prime \prime}\right.$ $\mathrm{N}, 13^{\circ} 33^{\prime} 02^{\prime \prime}$ E, elevation $2401 \mathrm{~m}$ a.s.l.), part of the SHARE (Station at High Altitude for Research on the Environment) network. The station is located in Central Italy on Mt. Portella, which is one of the peaks around the Campo Imperatore plateau, near to the Corno Grande, the highest peak on the Apennines chain (2912 m a.s.l.), and to the Calderone, the southernmost glacier of Europe (Figure 1). The position of the CMP station is such that it can be considered a free horizon site without local pollution sources: 
Assergi village (500 inhabitants, $1000 \mathrm{~m}$ a.s.l.) is at about $6 \mathrm{~km}$ of distance from CMP, L'Aquila town ( 70,000 inhabitants, $721 \mathrm{~m}$ a.s.l.) at about $16 \mathrm{~km}$, Rome town ( 3 million inhabitants, $20 \mathrm{~m}$ a.s.l.) at more than $100 \mathrm{~km}$, the Po valley (North Italy) at about $400 \mathrm{~km}$.

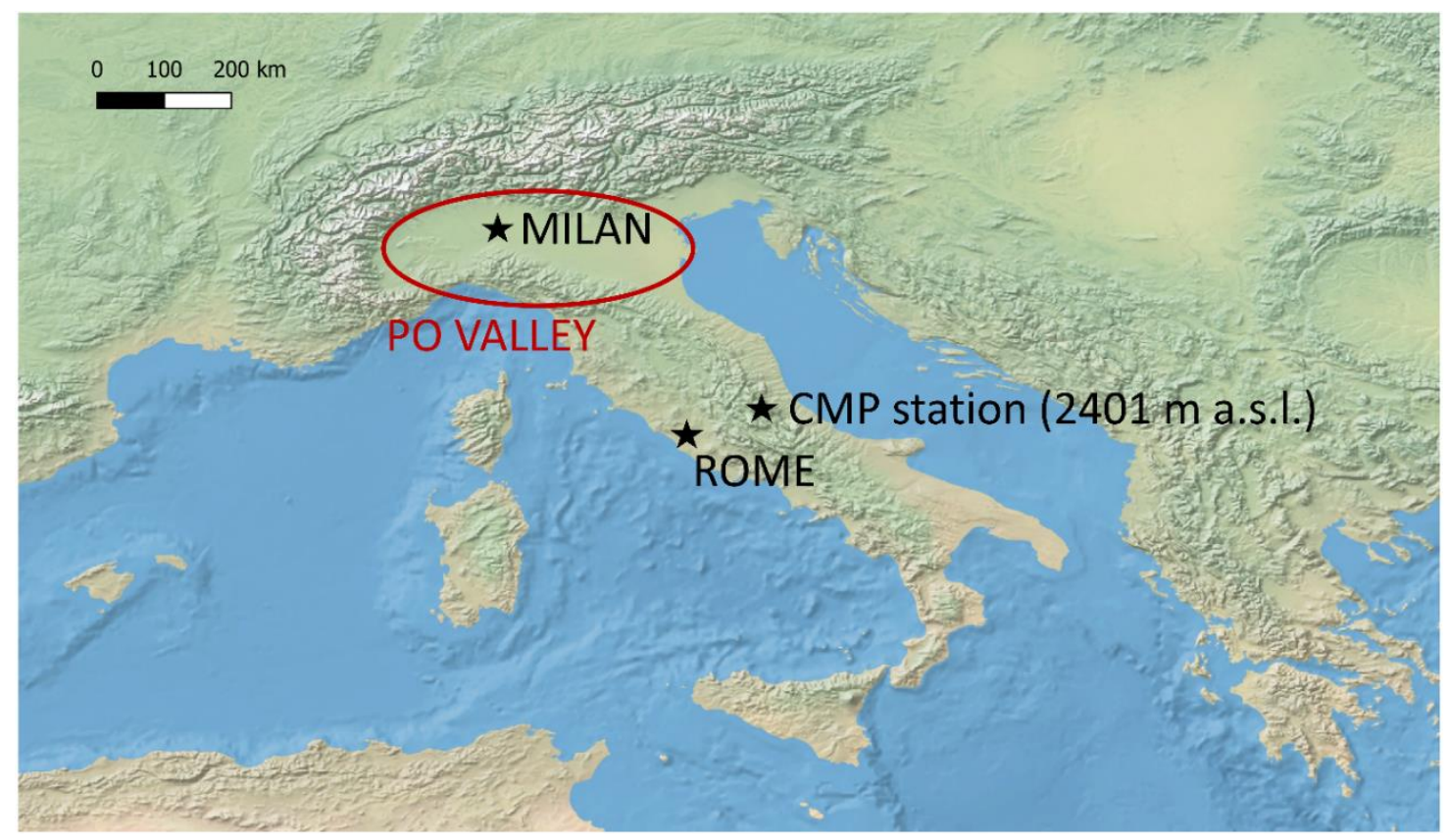

Figure 1. The location of the Mt. Portella (CMP) station in Central Italy. The raster map is from the Natural Earth website archive (available at http://www.naturalearthdata.com/).

In this study, we analyzed the data collected between September and November 2013 calculating their hourly average. The meteorological parameters were measured by a Vaisala instrument (model 520 WTX) and the solar radiation by the LSI Lastem srl DPA 153 sensor. The NO and $\mathrm{O}_{3}$ concentration were sampled using the $2 \mathrm{~b}$ nitric oxide (model 410 ) and the $2 \mathrm{~b}$ ozone (model 205) monitors, respectively.

Figure 2 shows the time series of all the parameters employed in this analysis: the temperature ranges between $271.65 \mathrm{~K}$ and $285.05 \mathrm{~K}$, the relative humidity between $11.9 \%$ and $94 \%$, the wind speed between $0.9 \mathrm{~m} / \mathrm{s}$ and $\mathrm{m} / \mathrm{s} 16.3 \mathrm{~m} / \mathrm{s}$. The background value of the NO registered average is about $2 \mathrm{ppb}$. The NO behavior presents three plumes registered, respectively, on 16 October, 17 October, and 3-5 November, which are highlighted with grey boxes in Figure 2, with concentrations up to $9.7 \mathrm{ppb}$ while the $\mathrm{O}_{3}$ levels vary between 27.3 and $59.8 \mathrm{ppb}$. These plumes are well characterized by the temperature ranging between $\sim 273 \mathrm{~K}$ and $\sim 279 \mathrm{~K}$, the relative humidity (RH) included between $\sim 30 \%$ and $\sim 94 \%$ and the wind direction that varies between the sectors North-West (NW) and North-East (NE). It is important to highlight that the meteorological conditions occurring during the three plumes are different. The first and third plumes, in fact, show a very high level of RH and low solar radiation, whereas in the second plume the RH decreases and the solar radiation increases. This suggests that the first and third plumes have been sampled in cloudy days, during which the photochemistry is less active compared to the second plume. Despite these considerations, the three plumes persist for more days (i.e., during both nighttime and daytime) indicating and confirming the important role played by transport in a remote site. 

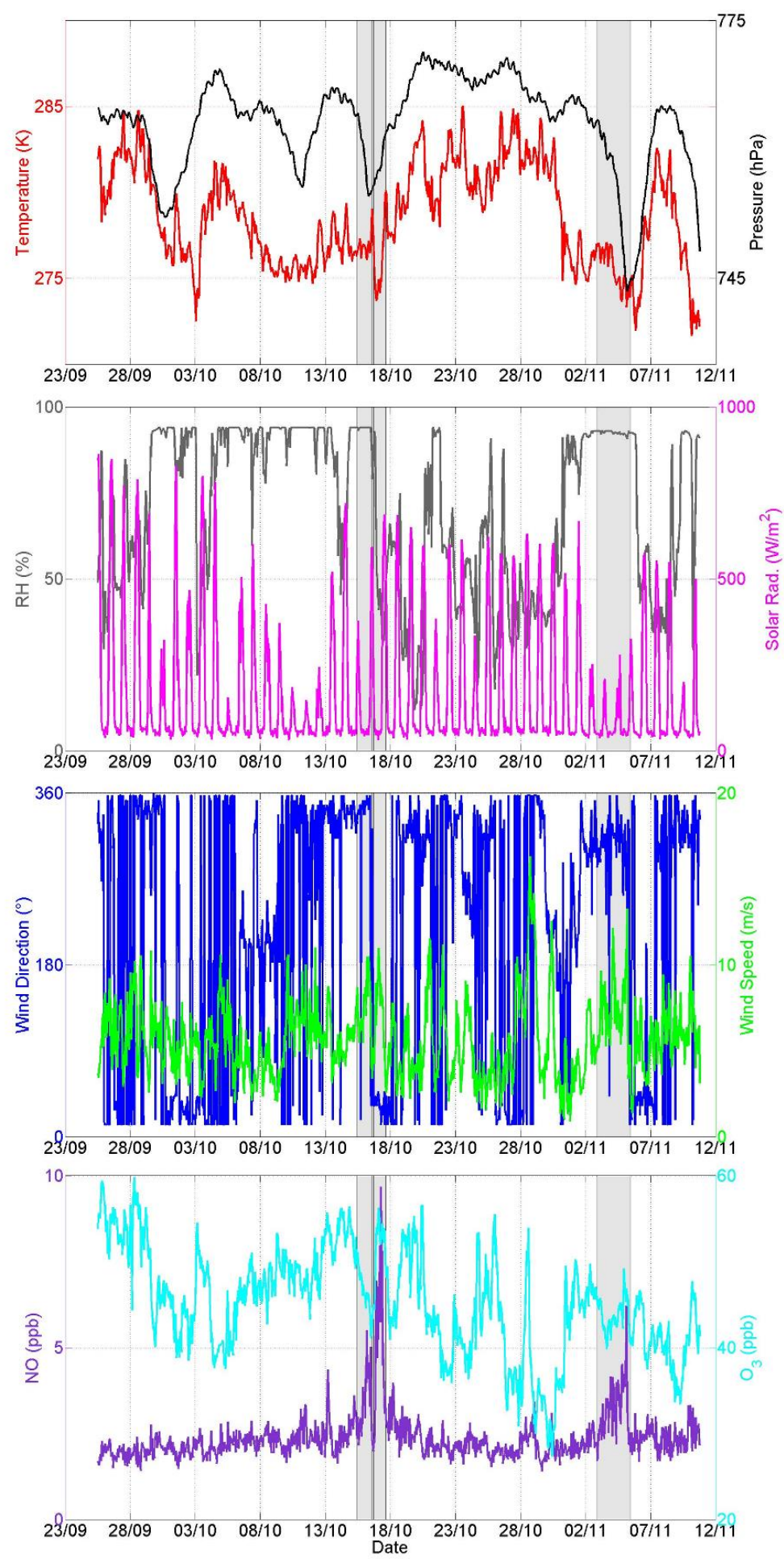

Figure 2. Time series of all the parameters of interest. The grey boxes highlight three plumes in the NO trend: two very close on 16 and 17 of October and the last on November (3-5 November 2013).

As expected in a remote site, the diurnal trend of $\mathrm{NO}$ and $\mathrm{O}_{3}$ does not show the typical evolution like in an urban environment where they are strongly linked to the photochemistry (Figure 2). However, the presence of three important plumes in the NO time series suggests analyzing in detail their origin and relation with the $\mathrm{O}_{3}$. To understand the origin of the three $\mathrm{NO}$ plumes, we employed an artificial neural network model varying the input parameters to deeply investigate the role played by the dynamical and photochemical process in a high mountain background site. 


\subsection{The Neural Network Model}

The artificial neural networks (ANNs) paradigm is inspired by the biological mechanisms that occur in the human brain. The ANNs, through a training and learning procedure, allows trend forecasts, including pattern recognition and classification. The basic architecture of ANNs considers three parts: the input layer, which contains the input neurons (or nodes), one or more hidden layers, in which there are neurons that are neither input nor output, and the output layer with the corresponding output neurons. Given the i-th neuron with an input vector $\mathrm{x}$ of $\mathrm{N}$ elements, first, each input datum is multiplied by the corresponding weight $\mathrm{W}$ and then they are summed (i.e., weight function, which can be expressed in matrix formalism as $\mathrm{W} \times \mathrm{x}$ ). $\mathrm{A}$ bias $\mathrm{b}$ is added to the last term to produce the net input (i.e., the net input function), which is eventually the argument of the transfer function $\mathrm{f}$ that generates the output value for the i-th neuron. The training procedure consists of the tuning of the bias and weight values, which are at first randomly initialized until the network performance is optimized. In our simulations, we used a single hidden layer feedforward neural network (FNN) with a different number of inputs neurons, depending on the simulation purposes, and one output neuron. In the FNNs the information propagates only forward through the network nodes, contrary to the recurrent neural networks in which there are feedback connections between the layers.

In this study, we made use of the deep learning toolbox available in Matlab. The FNN, employed in this study and schematically illustrated in Figure 3, uses a tan-sigmoid transfer function in the hidden layer and the linear one in the output layer.

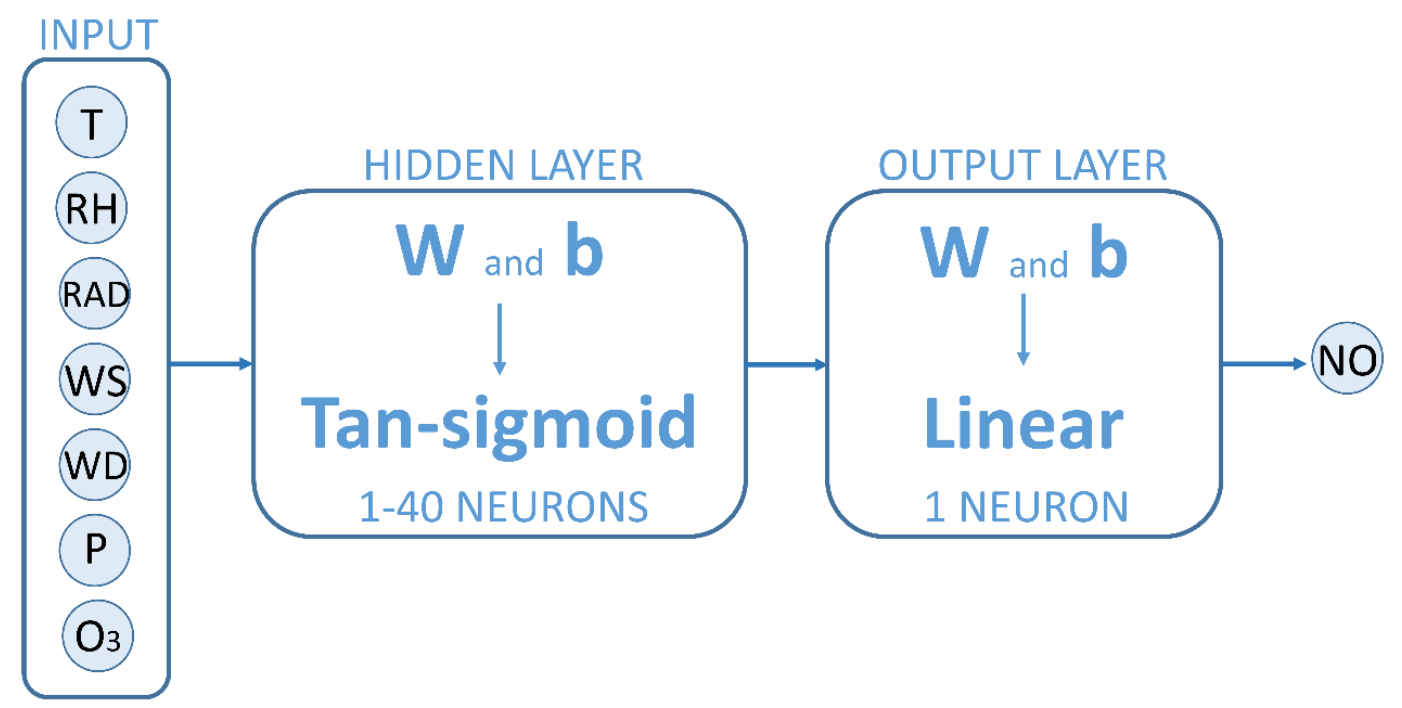

Figure 3. Schematic illustration of the feedforward neural networks (FFNs) architecture employed in this study. T: temperature; RH: relative humidity; RAD: solar radiation; WS: wind speed; WD: wind direction; P: pressure; $\mathrm{W}$ : weight; b: bias.

To keep our simulations reproducible, we fixed the seed: the same random values for initial weights and biases are produced when restarting the software (the random number generator functions are set to their default values).

In our analysis, we first carried out 3 simulations keeping all the FNNs settings equal and varying the input neurons as follows: (1) temperature $(\mathrm{T})$, pressure $(\mathrm{P}), \mathrm{RH}$, solar radiation, wind speed, and wind direction (henceforth, ALL simulations); (2) only the parameters describing the atmospheric dynamic, i.e., P, wind speed, and wind direction (henceforth, DYN simulations); (3) only the variables related to the photochemistry of the atmosphere, i.e., $\mathrm{T}, \mathrm{RH}$, solar radiation (henceforth, PHO simulations). Successively, we run 2 further simulations in which we included also $\mathrm{O}_{3}$ in the first and the last simulations described above (henceforward, $\mathrm{ALLO} 3$ and $\mathrm{PHOO} 3$ simulations, respectively). We run the FNNs varying the number of the neurons in the hidden layer from 1 to 40 and, to find the 
best simulations, for each number of neuron configurations, we did 30 trials of the model, i.e., we executed the FFNs 30 times during which the weights and biases varied in turn. Considering that the aim of our analysis was the NO simulation, we had only one output node that is the nitrogen oxide. The data have been divided into three sets: training $(70 \%)$, validation $(15 \%)$, and test $(15 \%)$. Each set is selected using indexes initially generated randomly, and then kept fixed for all the simulations: in this way, we fixed the selection of the dataset for all the simulations leaving only the weights and the biases variable. The network performance function employed in the FFNs is the mean square error (MSE), which controls the weights and biases tuning and optimization during the training process. To select the best simulation between the $40 \times 30$ cases that we generated with our approach, we choose different statistical parameters: the minimum MSE between the target output (i.e., the measured NO) and the network output (i.e., the NO modeled), the minimum normalized MSE (NMSE) that is the MSE divided by the variance of the measured $\mathrm{NO}$ and the maximum correlation coefficient $(\mathrm{R})$ between the NO measured and modeled [20].

\section{Results and Discussions}

Figures 4 and 5 show the time series of the measured NO and the modeled NO in the different simulations ran under distinct scenarios, as defined above, including or not the $\mathrm{O}_{3}$ as input node. The three NO plumes are highlighted in the lower panels of both Figures 4 and 5 .
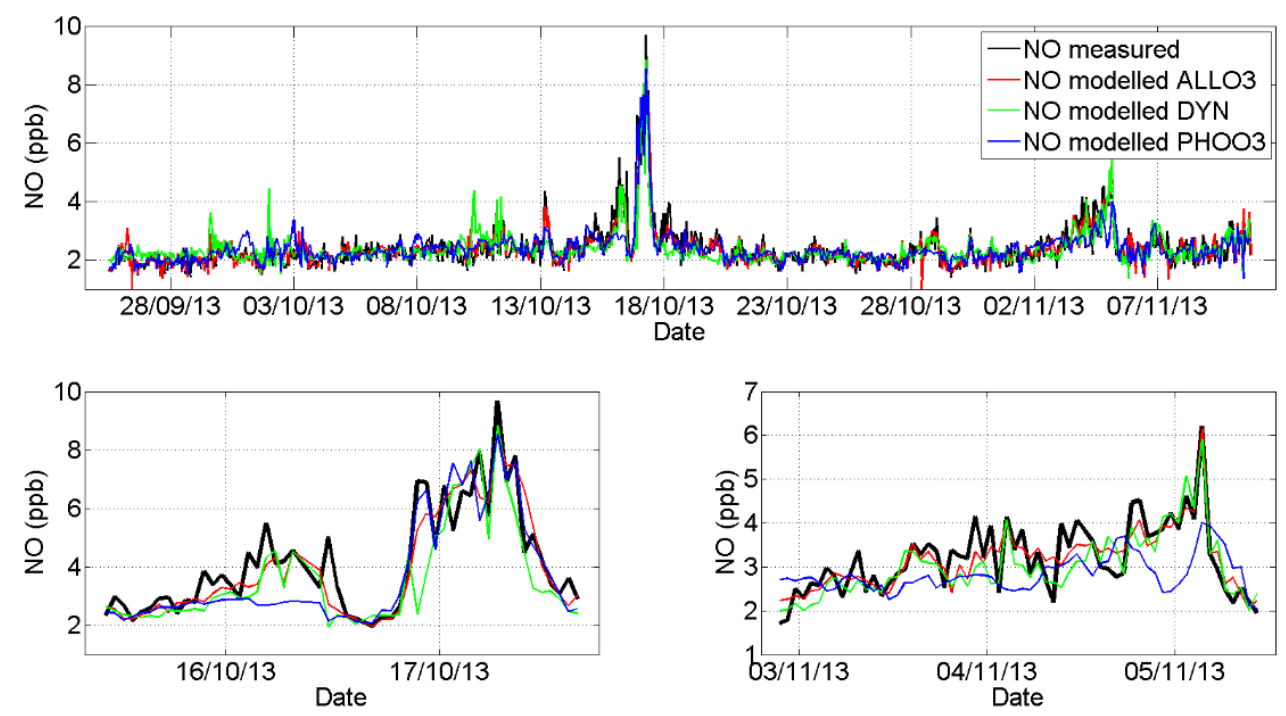

Figure 4. Upper panel: Time series of measured and modeled nitrogen oxide with three different scenarios for the input nodes (see text for more details). Lower panels: temporal magnification of the upper panel time series to highlight the three peaks of NO.

It is evident that the FNNs are able to reproduce the overall NO time series in almost all the simulation conditions: considering the entire time series, in fact, we found the best simulation of the NO using all the input parameters with an R between the NO modeled and measured at about 0.89 . However, focusing on the three NO plumes highlighted at the lower panels of Figures 4 and 5, the simulations with the photochemical parameters (blue lines) do not follow the measured NO behavior, whereas the NO modeled only with the dynamical inputs (green lines), reproduces the observations. In detail, both the $\mathrm{PHO}$ and $\mathrm{PHOO} 3$ simulations do not correctly describe the first plume (16 October 2013), even though in the second one (17 October 2013) these simulations overlap the measurements (especially the PHOO3). This result suggests that, as expected in a background site, the role played by transport is fundamental in characterizing the variations of the NO concentrations allowing one to describe some behavior excluding the photochemistry. The performance of the models and their 
ability to simulate the NO concentrations have been evaluated using four statistical indices: R, NMSE, fractional bias (FB), and factor of two (FA2). They are defined as follows [20]:

$$
\begin{gathered}
\mathrm{R}=\frac{\overline{\left(C_{O}-\overline{C_{O}}\right) *\left(C_{M}-\overline{C_{M}}\right)}}{\sigma_{C_{O}} * \sigma_{C_{M}}} \\
\text { NMSE }=\frac{\overline{\left(C_{O}-C_{M}\right)^{2}}}{\overline{C_{O}} * \overline{C_{M}}} \\
\text { FB }=2 \frac{\overline{C_{O}}-\overline{C_{M}}}{\left(\overline{C_{O}}+\overline{C_{M}}\right)} \\
\text { FA2 }=\frac{1}{2} \leq \frac{C_{0}}{C_{M}} \leq 2
\end{gathered}
$$

where $C_{O}, C_{M}, \sigma_{C_{O}}$ and $\sigma_{C_{M}}$ represent the observed and modeled concentrations and their standard deviations, respectively. Further details on these parameters and their interpretation can be found elsewhere [20]. Table 1 lists the values of these four indices for each simulation both considering the whole time series and the three single NO plumes.
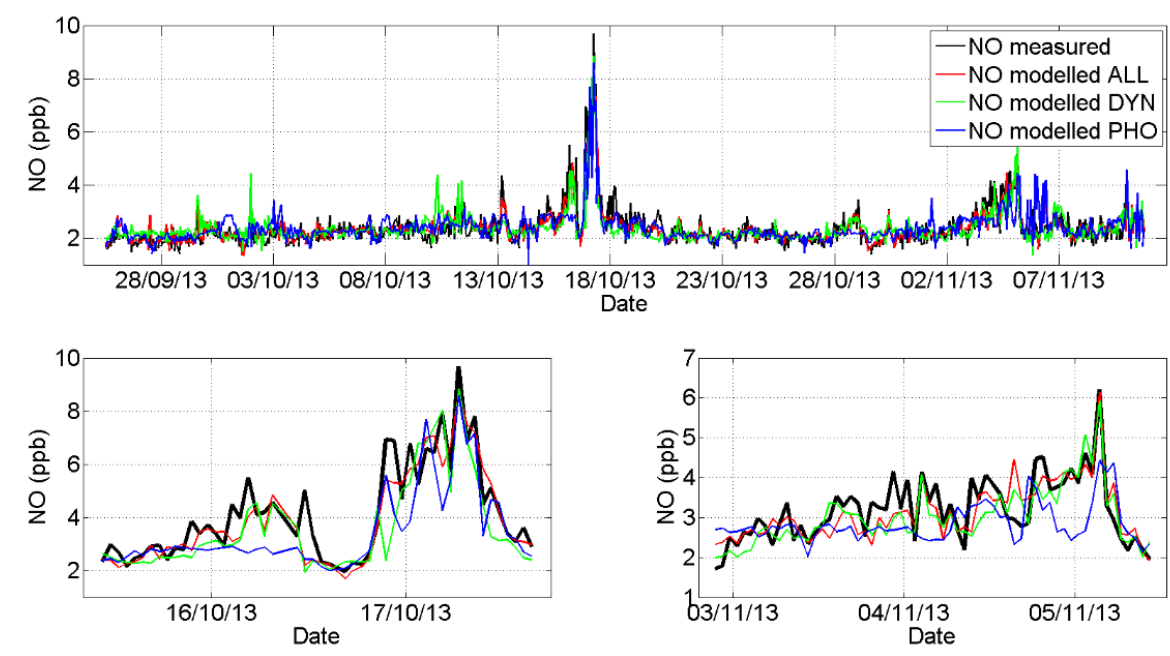

Figure 5. As Figure 4 but the modeled time series are the output of simulation without the inclusion of the $\mathrm{O}_{3}$ as input nodes.

The statistical parameters suggest that the simulations including $\mathrm{O}_{3}$ input typically are better than those without it. Moreover, it is proved that, in the first and third plume, the PHO and PHOO3 parametrization give the worst model results compared to the DYN simulations in terms of R, NMSE, and FB confirming that, in a high mountain site, the transport (expressed by the dynamical parameters) governs the measured NO plumes persistence more than the photochemistry. We evaluated the $t$-student test to further confirm that, in the first and third plumes, the NO time series modeled by the $\mathrm{PHO}$ and $\mathrm{PHOO} 3$ simulations are classified as not part of the population defined by the measured NO trend (i.e., they are statistically different). We rejected the null hypothesis, with a significance level $\alpha$ of 0.01 , evaluating the $t$-student test between the modeled and the measured NO for both the $\mathrm{PHO}$ and $\mathrm{PHOO} 3$ models in the first and third plume ( $\mathrm{h}=1$ in these cases). On the contrary, in the same plumes, we found that the null hypothesis is verified $(\mathrm{h}=0)$ when comparing the NO measured and modeled only with the dynamical parameters (DYN simulations). Moreover, it is important to notice that the first plume is generally modeled with worse results than the other two: this could be addressed, keeping the same FNNs architecture, considering other input parameters (such as visibility, lightning, etc.) that could improve the model performances. 
Table 1. Summary of the performance of the FFNs in the NO modeling for different input node simulations. $\mathrm{R}$ is the correlation coefficient, NMSE is the normalized mean square error, FB the fractional bias, and FA2 the factor of two. T: temperature; RH: relative humidity; P: pressure.

\begin{tabular}{|c|c|c|c|c|c|c|}
\hline Plume & Simulation & Input Parameters & $\mathbf{R}$ & NMSE & FB & FA2 \\
\hline \multirow{5}{*}{$\begin{array}{l}\text { Whole time } \\
\text { series }\end{array}$} & ALL & $\begin{array}{l}\text { T, RH, solar radiation, Wind } \\
\text { speed, Wind direction, } \mathrm{P}\end{array}$ & 0.8795 & 0.0208 & -0.0024 & 0.9991 \\
\hline & DYN & Wind speed, Wind direction, $\mathrm{P}$ & 0.7621 & 0.0389 & -0.0016 & 0.9955 \\
\hline & $\mathrm{PHO}$ & $\mathrm{T}, \mathrm{RH}$, solar radiation & 0.7379 & 0.0419 & -0.0041 & 0.9964 \\
\hline & ALLO3 & $\begin{array}{l}\mathrm{T}, \mathrm{RH} \text {, solar radiation, Wind } \\
\text { speed, Wind direction, } \mathrm{P}, \mathrm{O}_{3}\end{array}$ & 0.8890 & 0.0194 & -0.0027 & 0.9982 \\
\hline & PHOO3 & $\mathrm{T}, \mathrm{RH}$, solar radiation, $\mathrm{O}_{3}$ & 0.7997 & 0.0333 & $-7.8421 \times 10^{-4}$ & 0.9973 \\
\hline \multirow{5}{*}{ I plume } & ALL & $\begin{array}{l}\text { T, RH, solar radiation, Wind } \\
\text { speed, Wind direction, } \mathrm{P}\end{array}$ & 0.6072 & 0.0625 & 0.1029 & 0.9630 \\
\hline & DYN & Wind speed, Wind direction, $\mathrm{P}$ & 0.6164 & 0.0786 & 0.1580 & 0.9630 \\
\hline & $\mathrm{PHO}$ & $\mathrm{T}, \mathrm{RH}$, solar radiation & 0.3344 & 0.1273 & 0.2204 & 0.9259 \\
\hline & ALLO3 & $\begin{array}{l}\mathrm{T}, \mathrm{RH} \text {, solar radiation, Wind } \\
\text { speed, Wind direction, } \mathrm{P}, \mathrm{O}_{3}\end{array}$ & 0.7090 & 0.0492 & 0.1024 & 1 \\
\hline & PHOO3 & $\mathrm{T}, \mathrm{RH}$, solar radiation, $\mathrm{O}_{3}$ & 0.3686 & 0.1378 & 0.2423 & 0.9259 \\
\hline \multirow{5}{*}{ II plume } & ALL & $\begin{array}{l}\text { T, } \mathrm{RH} \text {, solar radiation, Wind } \\
\text { speed, Wind direction, } \mathrm{P}\end{array}$ & 0.9195 & 0.0276 & 0.0306 & 1 \\
\hline & DYN & Wind speed, Wind direction, $\mathrm{P}$ & 0.7996 & 0.0891 & 0.1208 & 0.9583 \\
\hline & $\mathrm{PHO}$ & $\mathrm{T}, \mathrm{RH}$, solar radiation & 0.8414 & 0.0731 & 0.1316 & 1 \\
\hline & ALLO3 & $\begin{array}{l}\mathrm{T}, \mathrm{RH} \text {, solar radiation, Wind } \\
\text { speed, Wind direction, } \mathrm{P}, \mathrm{O}_{3}\end{array}$ & 0.9094 & 0.0296 & 0.0076 & 1 \\
\hline & PHOO3 & $\mathrm{T}, \mathrm{RH}$, solar radiation, $\mathrm{O}_{3}$ & 0.9086 & 0.0295 & 0.0022 & 1 \\
\hline \multirow{5}{*}{ III plume } & ALL & $\begin{array}{l}\text { T, RH, solar radiation, Wind } \\
\text { speed, Wind direction, } \mathrm{P}\end{array}$ & 0.7913 & 0.0252 & 0.0210 & 1 \\
\hline & DYN & Wind speed, Wind direction, $\mathrm{P}$ & 0.8179 & 0.0256 & 0.0542 & 1 \\
\hline & $\mathrm{PHO}$ & $\mathrm{T}, \mathrm{RH}$, solar radiation & 0.4115 & 0.0747 & 0.1146 & 1 \\
\hline & ALLO3 & $\begin{array}{l}\mathrm{T}, \mathrm{RH} \text {, solar radiation, Wind } \\
\text { speed, Wind direction, } \mathrm{P}, \mathrm{O}_{3}\end{array}$ & 0.8620 & 0.0165 & 0.0089 & 1 \\
\hline & $\mathrm{PHOO} 3$ & $\mathrm{~T}, \mathrm{RH}$, solar radiation, $\mathrm{O}_{3}$ & 0.3351 & 0.0786 & 0.1161 & 1 \\
\hline
\end{tabular}

To confirm this assumption and to identify the origin of the air masses for the three plumes analyzed, the Hybrid Single-Particle Lagrangian Integrated Trajectory (HYSPLIT) model [25] has been employed. In detail, we evaluated the $24 \mathrm{~h}$-back trajectories selecting the departure time of each of them every half hour for all the three chosen plumes under analysis, fixing their start location to the geographical coordinates of the CMP station. Figure 6 reports the $24 \mathrm{~h}$-back trajectories as a function of the starting date: it is evident that air masses reached the CMP station from different locations in the Mediterranean area considering as starting time the occurrence of the first and third (dots and diamonds) or the second (squares) plumes. In detail, the air masses of the second plume (in which the photochemistry describes better the NO trend) originated from the Po Valley, a very polluted area in northern Italy [26]. On the contrary, the remaining two NO plumes (16 October 2013 and 3-5 November 2013) reach the CMP station from the Tyrrhenian Sea (western coast of Italy). Two back trajectories have been evaluated as part of the first and third plumes (i.e, those calculated starting on 16/10 at 12:30 and 06/11 at 00:00 in light pink and dark red in Figure 6), but they show a different provenance. This can be explained considering that they are relative to a transient phase in which the NO level varies between the first and second plume or it is returning to a background condition. 


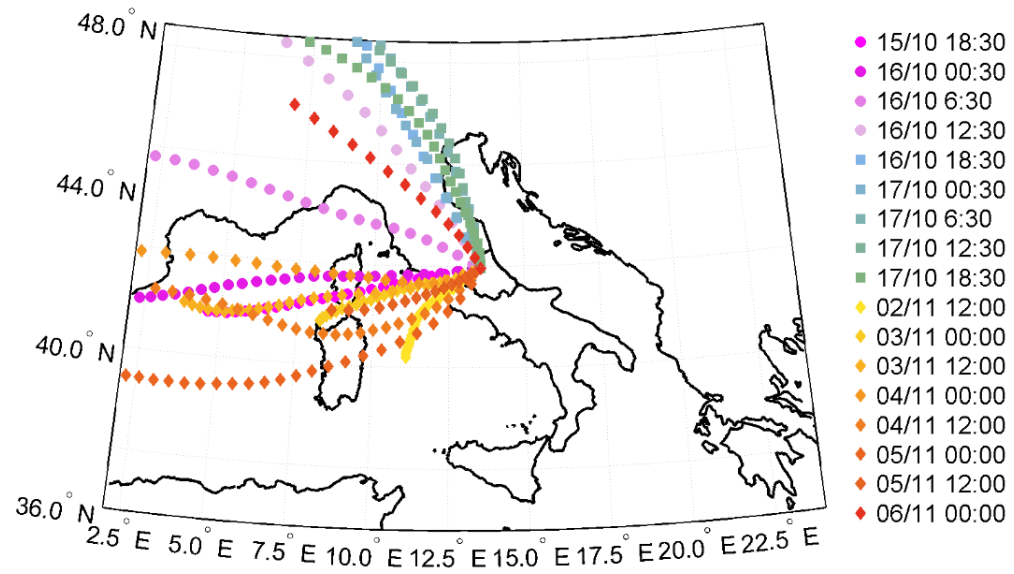

Figure 6. The Hysplit $24 \mathrm{~h}$ back-trajectories with as starting time the occurrence of the first and third plums (dots and diamonds, respectively) and of the second one (squares).

Lastly, the FNN results suggest that transport is a crucial factor for describing NO plume persistence in a high mountain site, even if it is also important to consider that, depending on the local meteorological conditions, the photochemistry can contribute or not significantly to the NO levels.

\section{Conclusions}

Single hidden layer FFNs have been developed to investigate the origin of three NO plumes measured between October and November 2013 at the Mt. Portella background station (2401 m a.s.l.). To evaluate the role played by the transport in this high mountain site, the input neurons have been varied in 5 different configurations of the FFNs. In details, we run five distinct simulations using different scenarios defined by the input parameters: (1) including all the available data (i.e., $\mathrm{P}, \mathrm{T}$, $\mathrm{RH}$, wind speed, wind direction, solar radiation), (2) using only the dynamical parameters (wind speed, wind direction, and $\mathrm{P}$ ) or (3) only the photochemical variables ( $\mathrm{T}, \mathrm{RH}$, solar radiation). The remaining two simulations have been run using the same input nodes of the first and third scenarios described above, but including also the $\mathrm{O}_{3}$ as an input. Analyzing the simulation outputs, we found that the input parameters that can be considered as a proxy of dynamical process, i.e., the atmospheric transport, describe better two of the NO plumes compared to those that are mainly a proxy of the photochemistry. Statistical tests (R, NMSE, FB, FA2, and t-student) have been applied to the modeled time series confirming that the atmospheric dynamic prevalently governs the NO plumes in this site. This study suggests that the FNN models are a very useful instrument to discriminate/characterize the origin of air masses in high mountain background areas and to simulate the local NO concentrations. However, further analyses are required to investigate the role played by the long-range transport in the high mountains, especially on the NO forecast in these sites. The air quality monitoring in background sites, in fact, allows one to study the impact of anthropogenic emissions on background conditions of the troposphere, especially considering that compounds such as $\mathrm{NO}_{x}$ and $\mathrm{O}_{3}$ could have a significant and negative impact on the ecosystem of the high altitude locations.

Author Contributions: Conceptualization, E.A. and P.D.C.; methodology, E.A. and P.D.C.; software, E.A. formal analysis, E.A.; investigation, E.A. and P.D.C.; resources, P.D.C., P.C. and P.B.; data curation, E.A.; writing-original draft preparation, E.A.; writing-review and editing, E.A., P.D.C., P.C. and P.B.; visualization, E.A.; supervision, P.D.C.; project administration, P.D.C., P.C. and P.B.; funding acquisition, P.D.C., P.C. and P.B. All authors have read and agree to the published version of the manuscript.

Funding: This research was partially supported by Fondi di Ricerca Dipartimentali (DiSPuTer-2018).

Acknowledgments: The Mt. Portella climatological station is part of the SHARE (Station at High Altitude for Research on the Environment) network and it has been partially funded by the SHARE project. The authors would thank Alfonso D'Altorio and Fabio Biancofiore for their support in the station installation and maintenance and fruitful discussion.

Conflicts of Interest: The authors declare no conflict of interest. 


\section{References}

1. IPCC. Climate Change 2013: The Physical Science Basis. In Contribution of Working Group I to the Fifth Assessment Report of the Intergovernmental Panel on Climate Change; Stocker, T.F., Qin, D., Plattner, G.-K., Tignor, M., Allen, S.K., Boschung, J., Nauels, A., Xia, Y., Bex, V., Midgley, P.M., Eds.; Cambridge University Press: Cambridge, UK; New York, NY, USA, 2013; p. 1535.

2. EEA. Air Quality in Europe-2019 Report No 10; Publications Office of the European Union: Luxembourg, 2019.

3. Bytnerowicz, A.; Fenn Mark, E.; Cisneros, R.; Schweizer, D.; Burley, J.; Schilling, S.L. Nitrogenous air pollutants and ozone exposure in the central Sierra Nevada and White Mountains of California-Distribution and evaluation of ecological risks. Sci Total Environ. 2019, 654, 604-615. [CrossRef] [PubMed]

4. Cheng, L.; Ji, D.; He, J.; Li, L.; Du, L.; Cui, Y.; Zhang, H.; Zhou, L.; Li, Z.; Zhou, Y.; et al. Characteristics of Air Pollutants and Greenhouse Gases at a Regional Background Station in Southwestern China. Aerosol. Air Qual. Res. 2019, 19, 1007-1023. [CrossRef]

5. Cristofanelli, P.; Landi, T.C.; Calzolari, F.; Duchi, R.; Marinoni, A.; Rinaldi, M.; Bonasoni, P. Summer atmospheric composition over the Mediterranean basin: Investigation on transport processes and pollutant export to the free troposphere by observations at the WMO/GAW Mt. Cimone global station (Italy, $2165 \mathrm{~m}$ a.s.1.). Atmos. Environ. 2016, 141, 139-152. [CrossRef]

6. Herrmann, E.; Weingartner, E.; Henne, S.; Vuilleumier, L.; Bukowiecki, N.; Steinbacher, M.; Conen, F.; Collaud Coen, M.; Hammer, E.; Jurányi, Z.; et al. Analysis of long-term aerosol size distribution data from Jungfraujoch with emphasis on free tropospheric conditions, cloud influence, and air mass transport. J. Geophys. Res. 2015, 120, 9459-9480. [CrossRef]

7. Balzani Lööv, J.M.; Henne, S.; Legreid, G.; Staehelin, J.; Reimann, S.; Prevot, A.S.H.; Steinbacher, M.; Vollmer, M.K. Estimation of background concentrations of trace gases at the Swiss Alpine site Jungfraujoch (3580 m a.s.1.). J. Geophys. Res. 2008, 113, 1-17. [CrossRef]

8. Kaiser, A.; Scheifinger, H.; Spang, W.; Weiss, A.; Gilge, S.; Fricke, W.; Ries, L.; Cemas, D.; Jesenovec, B. Transport of nitrogen oxides, carbon monoxide and ozone to the Alpine Global Atmosphere Watch stations Jungfraujoch (Switzerland), Zugspitze and Hohenpeissenberg (Germany), Sonnblick (Austria) and Mt. Krvavec (Slovenia). Atmos. Environ. 2007, 41, 9273-9287. [CrossRef]

9. Okamoto, S.; Tanimoto, H. A review of atmospheric chemistry observations at mountain sites. Prog. Earth Planet. Sci. 2016, 3, 34. [CrossRef]

10. Sigmund, A.; Freier, K.; Rehm, T.; Ries, L.; Schunk, C.; Menzel, A.; Thomas, C.K. Multivariate statistical air mass classification for the high-alpine observatory at the Zugspitze Mountain, Germany. Atmos. Chem. Phys. 2019, 19, 12477-12494. [CrossRef]

11. Deolal, S.P.; Brunner, D.; Steinbacher, M.; Weers, U.; Staehelin, J. Long-term in situ measurements of $\mathrm{NO}_{\mathrm{x}}$ and $\mathrm{NO}_{\mathrm{y}}$ at Jungfraujoch 1998-2009: Time series analysis and evaluation. Atmos. Chem. Phys. 2012, 12, 2551-2566. [CrossRef]

12. Gilge, S.; Plass-Duelmer, C.; Fricke, W.; Kaiser, A.; Ries, L.; Buchmann, B.; Steinbacher, M. Ozone, carbon monoxide and nitrogen oxides time series at four alpine GAW mountain stations in central Europe. Atmos. Chem. Phys. 2010, 10, 12295-12316. [CrossRef]

13. Cristofanelli, P.; Bonasoni, P. Background ozone in the southern Europe and Mediterranean area: Influence of the transport processes. Environ. Pollut. 2009, 157, 1399-1406. [CrossRef] [PubMed]

14. Campana, M.; Li, Y.; Staehelin, J.; Prevot, A.S.H.; Bonasoni, P.; Loetscher, H.; Peter, T. The influence of south foehn on the ozone mixing ratios at the high alpine site Arosa. Atmos. Environ. 2005, 39, $2945-2955$. [CrossRef]

15. Lanz, V.A.; Henne, S.; Staehelin, J.; Hueglin, C.; Vollmer, M.K.; Steinbacher, M.; Buchmann, B.; Reimann, S. Statistical analysis of anthropogenic non-methane VOC variability at a European background location (Jungfraujoch, Switzerland). Atmos. Chem. Phys. 2009, 9, 3445-3459. [CrossRef]

16. Pyrgou, A.; Hadjinicolaou, P.; Santamouris, M. Enhanced near-surface ozone under heatwave conditions in a Mediterranean island. Sci. Rep. 2018, 8, 9191. [CrossRef] [PubMed]

17. Cristofanelli, P.; Di Carlo, P.D.; Altorio, A.; Dari Salisburgo, C.; Tuccella, P.; Biancofiore, P.; Stocchi, P.; Verza, G.P.; Landi, T.C.; Marinoni, A.; et al. Analysis of summer ozone observations at a high mountain site in Central Italy (Campo Imperatore, 2388 m a.s.l.). Pure Appl. Geophys. 2013, 170, 1985-1999. [CrossRef] 
18. Jenkin, M.E.; Young, J.C.; Rickard, A.R. The MCM v3.3.1 degradation scheme for isoprene. Atmos. Chem. Phys. 2015, 15, 11433-11459. [CrossRef]

19. Grell, G.A.; Peckkam, S.E.; Schmitz, R.; McKeen, S.A.; Frost, G.; Skamarock, W.C.; Eder, B. Fully coupled 'online' chemistry within the WRF model. Atmos. Environ. 2005, 39, 6957-6975. [CrossRef]

20. Biancofiore, F.; Verdecchia, M.; Di Carlo, P.; Tomassetti, B.; Aruffo, E.; Busilacchio, M.; Bianco, S.; Di Tommaso, S.; Colangeli, C. Analysis of surface ozone using a recurrent neural network. Sci. Total Environ. 2015, 514, 379-387. [CrossRef]

21. Chen, J.; de Hoogh, K.; Gulliverd, J.; Hoffmanne, B.; Hertelf, O.; Ketzel, M.; Bauwelinckh, M.; van Donkelaari, A.; Hvidtfeldtj, U.A.; Katsouyannik, K.; et al. A comparison of linear regression, regularization, and machine learning algorithms to develop Europe-wide spatial models of fine particles and nitrogen dioxide. Environ. Int. 2019, 130, 1-14. [CrossRef]

22. Mclean Cabanerosa, S.; Calautitb, J.K.; Hughesa, B.R. A review of artificial neural network models for ambient air pollution prediction. Environ. Model. Softw. 2019, 119, 285-304. [CrossRef]

23. Arhami, M.; Kamali, N.; Rajabi, M.M. Predicting hourly air pollutant levels using artificial neural networks coupled with uncertainty analysis by Monte Carlo simulations. Environ. Sci. Pollut. R 2013, 20,4777-4789. [CrossRef] [PubMed]

24. Ibarra-Berastegi, G.; Elias, A.; Barona, A.; Sáenz, J.; Ezcurra, A.; Diaz de Argandona, J. Prediction of air pollution levels using neural networks: Influence of spatial variability. WIT Trans. Ecol. Environ. 2008, 116, 409-417.

25. Draxler, R.R. HYSPLIT4 User's Guide; Tech. Rep. NOAA Tech. Memo. ERL ARL-230; NOAA Air Resources Laboratory: Silver Spring, MD, USA, 1999.

26. European Environmental Agency (EEA). Air Quality in Europe-2018 Report. EEA Report, No 12. 2018. Available online: https://doi.org/10.2800/777411 (accessed on 15 March 2019).

(C) 2020 by the authors. Licensee MDPI, Basel, Switzerland. This article is an open access article distributed under the terms and conditions of the Creative Commons Attribution (CC BY) license (http://creativecommons.org/licenses/by/4.0/). 